\title{
$\underline{\text { A Realistic Look at Graduating Dance Majors: Problems and Solutions }}$
}

By: Jan Van Dyke

Van Dyke, Jan. 2010: A Realistic Look at Graduating Dance Majors: Problems and Solutions, Journal of Dance Education, volume 10/ number 3, pp 83-87.

This is an Author's Original Manuscript of an article whose final and definitive form, the Version of Record, has been published in the Journal of Dance Education, 2010 [copyright Taylor \& Francis], available online at: http://www.tandfonline.com/10.1080/15290824.2010.508697.

\section{Abstract:}

My life in dance has had its share of indecision, relocation, changes in direction involving two returns to school, and many years of living poor. The circuitous route I took to stay in the field made me into entrepreneurial artist and teacher and finally, a member of a university dance faculty. I wanted to live outside New York City and have a "professional" career in modern dance, and as a result, my path has involved figuring things out as I went along: learning what was necessary to make a journey full of twists and turns, even though it was not always easy to see where the next step should take me. Financially, the desire to dance trumped any economic ambitions, but even so, the difficulties and the lack of encouragement for artists in this culture-especially dancers — often made life hard, although I did have the benefit of family support in the early years. In this article I am suggesting that we break down the barriers between the academy and the real world in a serious way, by teaching what we know about staying in the field in spite of the twists and turns life provides. Before they leave our care, we do our best to thoroughly prepare our dance education majors for work in the schools. I think we need to give young artists more preparation than simply learning to dance.

Keywords: dance education | dance graduates | dance majors | higher education | dance professionals

\section{Article:}

My life in dance has had its share of indecision, relocation, changes in direction involving two returns to school, and many years of living poor. The circuitous route I took to stay in the field made me into entrepreneurial artist and teacher and finally, a member of a university dance faculty. I wanted to live outside New York City and have a "professional” career in modern dance, and as a result, my path has involved figuring things out as I went along: learning what was necessary to make a journey full of twists and turns, even though it was not always easy to see where the next step should take me. Financially, the desire to dance trumped any economic ambitions, but even so, the difficulties and the lack of encouragement for artists in this culture-especially dancers — often made life hard, although I did have the benefit of family support in the early years. In this article I am suggesting that we break down the barriers between the academy and the real world in a serious way, by teaching what we know about staying in the field in spite of the twists and turns life provides. Before they leave our care, we do our best to thoroughly prepare our dance education majors for work in the schools. I think we need to give young artists more preparation than simply learning to dance.

I grew up wanting to be a dancer and by my teenage years, I was studying dance four or five afternoons each week and teaching younger students on Saturday mornings. No one in my family was in the arts, so I 
had no idea what life as a dancer might require other than dancing, and no one thought to advise me. My teachers encouraged me and I loved dancing. I went to college in Wisconsin and majored in dance far from the industry center, graduating without ever having a piece of choreography produced onstage. I still had not had a conversation about how to make it work financially.

This is not so very different from the situation many students majoring in dance find themselves in today, although it is changing, bit by bit. At my school, the University of North Carolina at Greensboro, we offer a one-week field trip to New York City open to all majors, with classes, concerts, and interviews with working dancers, but our related course work is limited. Only the BFAs are required to take a course in Career Management, although the BA (dance studies and dance education) students are allowed to elect it. Otherwise, whereas the dance education students are taken into the schools numerous times and given a semester of student teaching, non-dance-education BAs get no career advice as part of the formal curriculum. In terms of choreography, the BFAs are given a choice of producing a piece of choreography as a culminating project or performing in a faculty work. BA students can contribute work to the BFA concert if they have completed the three-course choreography progression, and everyone can audition choreography for the annual student-produced show. On graduation it seems unlikely that many of our new alumni know much more than I did about how to proceed.

I spent my first year out of college in New York City taking classes and trying to find work. During that year, I shared an apartment with two friends, both also recently graduated dance majors from Wisconsin, both as clueless as I was. We had different financial situations, illustrating the full range of ways in which privilege is associated with pursuing a career in the arts. Judy came from a wealthy family and had no worries. She studied and auditioned in New York for seven years before returning to her hometown to begin teaching and making dances on her own. Kathy needed to work right away, and as soon as we got to town, she took a nine-to-five job as a secretary in a small office. The demands of that work soon became the center of her life, and to my knowledge, she never took a dance class again. This kind of "dropping out” still happens today, although it is often more gradual. As young dancers face the financial realities of the profession free of the structure school provides, many gradually drift away.

My parents had agreed to pay for my New York City classes for one year. They were generous in their support, but I was without a plan. It turned out that the teacher I had wanted to study with was in Europe on an extended tour, and not knowing what else to do, I invested the money I'd been given at the same studio where my roommate Judy was taking class. After a matter of weeks I knew I was studying a technique I didn't like, being taught in a manner I could not respect. I began to dread going, and without money or ideas, I gradually stopped attending any classes at all. I studied modeling and considered becoming an airline stewardess. In the spring of that first year, however, discouraged and desperate after trying with no luck to find work in those fields, I began auditioning as a dancer. When I quickly landed a paying, union job in a summer Broadway series in Charlotte, North Carolina, I knew I had been sent a message. By the end of a very good summer working as a paid dancer, I decided that dancing probably was what I was qualified and trained to do-and maybe it was the only thing.

I had to think seriously about how to proceed. My future in musical theater was limited, because, after performing seven different musicals in eight weeks, it was clear that I couldn't carry a tune. Family support had run out and I understood that I needed to work, so after a few weeks searching for an apartment, I gave up on New York and went back to my hometown of Washington, DC. I took a job 
teaching at the studio where I'd grown up, and it quickly became obvious that, even though I'd taught there on Saturday mornings while in high school, I did not know much about teaching and learning. Additionally, I began to see that if I wanted a professional life as a dancer-the only goal I'd ever really had-in a city like Washington in the 1960s, I was going to have to create my own dances and get them produced. This slow realization began a period of trial and error that continues today, learning to teach and make dances, figuring out how to produce concerts that audiences will attend, how to advertise, and how to raise money. An earlier, formal introduction to the realities of the field would have greatly helped me in understanding the business world and what my options were.

\section{The Problem}

As it was, I learned as I went. The kind of trial and error I experienced was often frustrating and timeconsuming: an important learning tool, no doubt, but learning from failure is much easier with the help of an experienced and nurturing guide. To have been given direction, so that failures were informed, would have been invaluable, providing a perspective on how I was doing. Inexperience and ignorance of this sort make it hard to know how to avoid making the same mistakes again and whether to continue trying. Looking back now, I can see that if I had had other options, if some of my attempts at other kinds of work had been more successful, I might well have opted for an easier path. As it was, I made the effort to learn what I needed to achieve my goals. It seemed I would be making a living by teaching and my family agreed to subsidize my career once more to go back to school, giving me crucial help in making this kind of career turn. I earned an MA to learn about education and choreography and after that, it was a matter of figuring out how to make it happen.

I think of this time now as an apprenticeship with successful (and some not so successful) mentors. I taught in several different studios and in observing how studios differ, I learned quite a lot that continues to influence my work today, things like the difference between teaching children and adults, and the frequent trade-off between teaching a good technical and rhythmic base and producing big recitals. I danced in small companies and watched how artistic decisions were made, how important relationships among dancers can be to company culture, and how the number of hours a group works each week really does affect the overall production values of their shows. And, importantly, I began to understand that being an artist is as much about business as about making art.

Eventually I opened my own studio and started a company. With the help of colleagues, I made my studio space into an informal theater and produced concerts. I learned how to write grants by trial and error, and to do publicity by doing it, and in due course, I toured internationally as a teacher and choreographer/performer. Before accepting an academic job in 1989, I had spent nearly 20 years as a freelancer, for a while working as a solo artist, and then, for a long time, directing a company and running a school and performance space.

Dancers need opportunities_-all artists do — and they need to know how to open doors for themselves, because not all have the privilege of support that I experienced. The path of an artist's career twists and turns and changes as we do, depending on age and ability. With entrepreneurial preparation, dance artists can begin to see every obstacle as a chance to try another way of doing things. With guidance, our students can learn from the outset that determination is the key to finding a path, and that options exist within the field. Otherwise, too many invest heavily in a backup plan that will remove them from the dance world. 
Entrepreneurialism is often challenging for dance artists, because our training is intensely self-centered, silent, and internal. We usually learn by following directions and taking criticism, which does not encourage independent thinking. Handing important decisions over to administrators and directors continues our passivity, while giving away the means of deciding the direction of our profession. As it is now, our system of educating and training dancers maintains the financial barriers to sustaining a long career in dance: Too many dance artists—-like me-grow up focused strictly on building technique without learning enough about teaching and the other arts, to say nothing about politics, keeping a budget, and how the world works.

Possible Solutions

Dancers heading out into the world will face all kinds of choices to support their artistic projects, and they will succeed more often if they are prepared. What if dance students had to complete summer or winter internships in the community, working with studios, theaters, and nonprofit agencies? This is a win-win situation for students and the organizations. More interaction with the local dance community is a reality check that will help to bring aspects of a dancing life into focus. Asking those faculty members who have worked outside academia to discuss their lives and choices will illustrate another path. Stressing the importance of seeking out mentors, developing good writing skills, and understanding project (think rehearsal) management will only help students to value what they already have access to. Developing aspects of the curriculum to illustrate how dance artists actually live will not only give us all more control of the field and our own lives over the long term, but broaden the accessibility of our art and expand the community with which we share our work.

Over the years, I have become a strong advocate against the narrowly focused education most dancers receive. As teachers, I think we should be talking with our students from the very beginning about possibilities within the profession and how best to prepare for them. This can be done both informally and as formal presentations within classes and as assembly meetings. Dance cannot afford the attrition it suffers every year after college graduations. Those earning dance degrees need more knowledge and experience than how to dance or even how to make dances. Contemporary dancers need to know, before they face the hard choices about their future, that even if they "make it" and get into a touring company, they will not necessarily have a secure lifestyle. They need to be given help thinking entrepreneurially, along with strategies for problem solving, critical thinking, and ways of understanding the realities of the profession. Dance has so much to offer today's world, it is to our advantage to expand dancers' capabilities. As their teachers, even if we are focused on training future performers, our 21st-century challenge lies in giving merit and support to multiple aspects of a life in dance. A professional performing career is relatively short and, if we want to keep the talent and experience older dancers have to offer, performance should be viewed as only one step in a progression of meaningful associations with the field. Transitioning can be easy if one has been thinking in those terms, preparing to move into a related area involving a familiar community and lifestyle. The profession would be well served if dancers planned to carry their invaluable training and experience into the next career phase as they morph into, among other possibilities, writers, teachers, dance and physical therapists, arts administrators, scholars, Webmasters, costumers, lighting designers, company directors, producers, and choreographers.

As I approached the end of my performing career, I went back to graduate school again for a doctorate and took my current job, teaching dance at UNC Greensboro. I still have a company that performs my 
work and I still perform occasionally, and because I still want to show my work, my focus now is on building a community and an audience for dance in the surrounding area. Creating a local structure of organizations and opportunities within which artists can operate, whether or not they have financial support, seems crucial. To help toward that goal, I direct a nonprofit business that manages a communitybased dance school and produces the NC Dance Festival, now in its 20th year of touring the state presenting work by North Carolina dance artists.

Is it fair to generalize based on my own experience? Although my journey might be different from others in its details, the problems have not changed, and the lack of support-both financial and educational—is still a major obstacle. A well-known dance artist and educator once said in conversation that she considered survival in the field a major mark of success, and given the dropout rate, I would have to agree. It seems that if artists' lives and priorities were better understood by dance students, if there were accessible role models in all our communities and an education that included aspects of what young artists can expect to face as they make their way, dance would be an easier choice.

\section{Reconceptualizing Dance Training and Preparation}

As it is, out of concern that a college degree in dance provides no dependable means of earning a living after graduation, young people are often told that the arts are not a sure thing: They need an alternative plan, a way to make a steady salary. I think we can begin to effect a change in this area of thought—at least in the concept of "alternative"-by expanding how we view a career in dance. It does not have to be an either-or choice. It will involve reconceptualizing dance training to include the related areas that can support a lifetime in dance: teaching, body work, writing, video, and so on, and making this kind of thinking important to our students by building it into the curriculum. This will mean setting up opportunities for off-campus internships, or shadowing an area studio director, or making a survey of local dance companies to assess their budgets, governance, schedules, pay, selection processes, and so on. Providing occasions for guest artists and faculty alike to tell the story of their careers makes good use of resources at hand.

Other, broader curricular changes include designing programs where students can easily double-major in complementary disciplines to get more mileage out of their dance preparation and training, or for those who are interested, conceiving a way for students to get their degrees through interdisciplinary work in other departments, to gain experience in areas like psychology, marketing, theater technology, athletic training, and so on. Career coaching should not only prepare students for work, but teach them to honor their own interests and abilities. Life plans require the kind of self-knowledge that includes knowing whether one is more comfortable with a secure income that will require a part-time job, or if the flexibility of self-employment is more important. With a broad view of possibilities, young dancers can more easily prepare for and accept the rigors of the field if the curriculum we offer includes this kind of thinking.

When talking to students and parents about career issues, I agree that yes, most dance artists do want skills other than dancing. And, I say, it is important to choose a second area that will put food on the table, while allowing time and energy for rehearsals and continued technical training, perhaps something that involves working with other artists so that the network continues to grow-like making costumes, bookkeeping, arts administration, studio teaching, lighting design, or Web site management. A little 
creative thinking is important here. Additional skills can be developed as they are needed. Graduate school is a possibility down the road.

Most important, I tell them, is that if they are serious about staying in this field, their work should contribute to that goal. A day job in a completely unrelated field will only draw dancers out of the arts, involve their energies for up to eight hours a day, create other priorities, and possibly, associate them with folks who do not value the arts, as it did for my New York roommate Kathy. A second college degree in finance or elementary education might sound like a good idea, but in many cases, it will also create demands and options that can make it too tempting to take an easier path when the going gets rough. Whatever they decide to do, it should be something that teaches more about how the dance world works. Dance administration; teaching dance; teaching other disciplines like yoga, Pilates, and Alexander Technique; dance video work and photography; designing costumes; technical production; and writing about dance are only a few areas that will inform their artistry, while nourishing the local scene and recognizing and creating opportunities for themselves and other artists.

At graduation, as artists, we need to feel prepared to face the hard decisions and be creative about choosing a lifestyle. It is not an easy road, and one might have to be prepared to forgo amenities to which they have become accustomed. This can be challenging. It will also be fulfilling though, to live a life based on shared values within a wide-ranging community filled with folks who understand the importance of the arts for all people. 